\title{
Incisional Hernia: A Prospective Study
}

\author{
Anurag Chauhan ${ }^{1}$ Devendra K. Prajapati ${ }^{1}$ Vikas Singh ${ }^{1}$
}

Address for correspondence Devendra K. Prajapati, MS, FIAGES, FMAS, FALS, 305 Metro Tower, New Collectorate Road, City Centre, Gwalior, Madhya Pradesh 474001, India (e-mail: dr.dev1982@gmail.com).

Int J Recent Surg Med Sci 2021;7:85-87.
Abstract
Keywords
- incisional hernia
- hernia
- ventral hernia
- abdominal surgery complications
- risk factor
- inguinal hernia

An incisional hernia is being a universal problem and topic of discussion worldwide. There is no clear-cut guideline of abdominal wall closure after major abdominal surgeries that can effectively prevent the occurrence of incisional hernia. We found out that most of the patients presented with pain over previous surgery scar with swelling. The defect was usually larger than $2 \mathrm{~cm}$. Most postoperative patients complaint of pain, seroma, and hematoma formation. There was a minimal recurrence rate after onlay mesh repair in our setup.

\section{Introduction}

Incisional hernia can be described as protrusion of abdominal contents with peritoneum through the scar or weak part that develops after previous surgery. It includes a type of hernia that is caused by a poorly healed surgical site of prior operation. Midline scar hernias are one of the most common incisional hernias. ${ }^{1,2}$

An incisional hernia develops commonly due to high tension midline closure and surgical site infection postoperatively. This hernia increases in size gradually and results in severe discomfort to the patient, pain, and sometimes may present with intestinal obstruction too. It is found in the literature that around $50 \%$ of this hernia starts after 2 years of postsurgery and $75 \%$ within 3 years. And this risk increases in later years gradually. ${ }^{3-5}$

Incisional hernias are very difficult to manage in any setup. Because of its frustrating results during treatment which includes surgical site infection, skin necrosis, and seroma formation.

This study is an effort to evaluate clinical presentations and management of incisional hernia in our setup.

\section{Aims}

1. Common clinical presentation of incisional hernia.

2. The postoperative complication of incisional hernia repair in our setup.

\section{Materials and Methods}

This prospective observational study has been done at a tertiary care center. This study was performed in the Department of Surgery, J.A. Group of Hospitals, Gera Raja Medical College, Gwalior, Madhya Pradesh, India, from January 2019 to June 2020.

A total of 40 patients have been studied who were admitted in the department of surgery with a diagnosis of incisional hernia of ages between 12 and 65 years with complain of pain and discomfort at the site of the swelling, with a history of previous surgery and postoperative complication and willing for surgery due to cosmetic purposes.

Detailed clinical examination and appropriate investigations like blood, urine, liver function test, renal function test, bleeding profile, hepatitis B surface antigen, and human published online

July 7,2021
DOI https://doi.org/

$10.1055 / \mathrm{s}-0041-1731917$

ISSN 2455-7420 (c) 2021. Medical and Surgical Update Society.

This is an open access article published by Thieme under the terms of the Creative Commons Attribution-NonDerivative-NonCommercial-License, permitting copying and reproduction so long as the original work is given appropriate credit. Contents may not be used for commercial purposes, or adapted, remixed, transformed or built upon. (https://creativecommons.org/licenses/by-nc-nd/4.0/).

Thieme Medical and Scientific Publishers Pvt. Ltd. A-12, 2nd Floor, Sector 2, Noida-201301 UP, India 
immunodeficiency virus, along with chest X-ray and electrocardiogram were performed. Ultrasonography was done in every case for assessment of the defect size in patients along with the search for any existing comorbid diseases. All data were collected in a predefined pro forma after the due consent of the patient.

\section{Observations and Results}

Our study was conducted over 40 patients admitted from January 2019 to June 2020 in the Department of Surgery, Gajra Raja Medical College, and J.A. Group of Hospital, Gwalior. After collection and analysis of data the following results came out in view.

\section{Symptoms Wise Distribution}

In our study, the most common symptom was swelling with pain (55\%). The swelling was visible on standing or exertion. The pain was dragging in nature. Other $45 \%$ cases presented with swelling only (-Table $\mathbf{1}$ ).

Table 1 Distribution of cases according to symptoms

\begin{tabular}{|l|l|l|}
\hline Occupation & No. of patients & Percentage \\
\hline Swelling & 18 & 45 \\
\hline Swelling and pain & 22 & 55 \\
\hline Pain & 00 & 00 \\
\hline
\end{tabular}

Table 2 Distribution of cases according to the size of the defect

\begin{tabular}{|l|l|l|}
\hline $\begin{array}{l}\text { Size of } \\
\text { defects }(\mathrm{cm})\end{array}$ & No. of patients & Percentage \\
\hline$<2$ & 5 & 12.5 \\
\hline $2-4$ & 17 & 42.5 \\
\hline$>4$ & 18 & 45 \\
\hline
\end{tabular}

Table 3 Distribution of cases according to the procedure of operation

\begin{tabular}{|l|l|l|}
\hline $\begin{array}{l}\text { Procedure of } \\
\text { operation }\end{array}$ & No. of patients & Percentage \\
\hline Only & 35 & 87.5 \\
\hline $\begin{array}{l}\text { Anatomical closure } \\
\text { (resuturing of the } \\
\text { defect) }\end{array}$ & 05 & 12.5 \\
\hline
\end{tabular}

Table 4 Distribution of cases according to postoperative complications

\begin{tabular}{|l|l|l|}
\hline $\begin{array}{l}\text { Postoperative } \\
\text { complications }\end{array}$ & $\begin{array}{l}\text { No. of } \\
\text { patients }\end{array}$ & Percentage \\
\hline Seroma formation & 02 & 05 \\
\hline Hematoma formation & 03 & 7.5 \\
\hline Wound infection & 03 & 7.5 \\
\hline
\end{tabular}

\section{Defect Size Wise Distribution}

In our study, the defect size of incisional hernia in the abdominal wall was calculated by ultrasonography and was noted less than $2 \mathrm{~cm}$ in 5 patients (12.5\%) and more than $4 \mathrm{~cm}$ in 18 patients (45\%). Seventeen patients $(42.5 \%)$ had defects ranging from 2 to $4 \mathrm{~cm}$ (-Table 2 ).

1. Operative Procedure Wise Distribution

2. The anatomical repair was done in 5 patients.

3. Mesh onlay repair done in 35 patients (-Table 3 ).

\section{Postoperative Complications}

In our study, all 40 patients had pain which was treated with analgesics. Two patients had seroma formation which was treated by aspiration and dressings. Three patients had hematoma formation which was also treated by drainage and dressings. Three patients had wound infection which was treated with antibiotics according to culture and sensitivity reports. There was no mortality noted in the postoperative course in this study (-Table 4).

\section{Discussion}

An incisional hernia is being a universal problem and topic of discussion worldwide. There is no clear-cut guideline of abdominal wall closure after major abdominal surgeries that can effectively prevent the occurrence of incisional hernia. This prospective study was conducted on over 40 patients in the above-mentioned duration in the department of surgery. And we have observed various symptoms, distribution of hernias on the basis of their size, surgeries we performed, and different complications after it.

Most patients of incisional hernia presented with abdominal swelling and pain (55\%). While other patients of incisional hernia presented only with swelling over the abdomen (45\%). This presentation in our study matches the internationally reported presentations.

In our study, $45 \%$ of the patient had defect size of more than $4 \mathrm{~cm}$ while $42.5 \%$ of patients had defect size between 2 and $4 \mathrm{~cm}$. Jack believes that mesh repair is the best method of repair for large ventral hernia but has not specified the size of the defect. ${ }^{6}$

A systematic review found that hernia repair without prosthetic mesh is associated with unsatisfactory recurrence rates of 12 to $54 \%$, whereas hernia repairs with mesh result in recurrence rates of 2 to $36 \%$. It is now believed that only the smallest (less than $3 \mathrm{~cm}$ ) incisional hernia should be mended by primary tissue approximation with sutures. A population-based study of 10,882 patients in the United State found an elevation in the frequency of the utilization of synthetic mesh from 35\% in 1987 to 65\% by 1999 .

In our study polypropylene mesh and also the suture material of the identical type was used to repair the incisional hernias and also the technique of the repair was decided by the tone of the abdominal muscle, size of the hernia defect, whether this defect might be approximated without tension, 
and general condition of the patient. Thirty-five out of 40 patients were treated with onlay polypropylene mesh repair and 5 with anatomical resuturing of the defect.

Wound infection occurred in 3 patients, while 2 patients had seroma formation after mesh repair.

There were no recurrences noted in our study; however, the follow-up period was variable and brief to comment upon. Usher et $\mathrm{al}^{7}$ reported zero recurrence in 48 patients who were managed by polypropylene mesh repair. Burger et $\mathrm{al}^{8}$ revealed a 10 -year cumulative rate of recurrence of $63 \%$ in anatomical repair and 32\% in mesh repair. The recurrence rate thus varies in several studies but all studies support mesh repair for minimizing the recurrence rate.

With complete patient evaluation, adequate skin preparation before surgery, accurate surgical technique, nonabsorbable sutures use for musculoaponeurotic tissue, suction drain use, perioperative broad-spectrum antibiotics use, nasogastric aspiration, early ambulation, and chest physiotherapy, complication rates in our study was restricted to a minimum.

With prosthetic mesh, defects of any size may be repaired without tension. The polypropylene mesh, by inducing inflammatory response sets up scaffolding that successively induces the synthesis of collagen.

Thus, the prevalence of mesh repair over suture repair must be accounted for.

\section{Conclusion}

Forty cases of incisional hernia, admitted to our hospital were studied. In this study, the statistical data and analysis of the cases studied for an incisional hernia during the period January 2019 to May 2020 are presented.

Most of the patients presented with swelling and pain (55\%) at the previous surgical scar, out of which 35 patients had more than $2 \mathrm{~cm}$ defect size of incisional hernia. Thirty-five out of 40 patients had been repaired by onlay mesh repair. In our study, all 40 patients suffered from postoperative pain which was treated with analgesics. Two patients had seroma formation which was treated by drainage and dressings. Three patients had hematoma formation which was also treated by aspiration and dressings. Three patients had wound infection which was treated with antibiotics according to culture and sensitivity reports. There was no recurrence in our study though the follow-up period was inadequate to make a correct evaluation of recurrence.

\section{Conflict of Interest}

None declared.

\section{References}

1 Korenkov M, Paul A, Sauerland S, et al. Classification and surgical treatment of incisional hernia. Results of an experts' meeting. Langenbecks Arch Surg 2001;386(1):65-73

2 George $C D$, Ellis $H$. The results of incisional hernia repair: a twelve year review. Ann R Coll Surg Engl 1986;68(4):185-187

3 Wright BE, Beckerman J, Cohen M, Cumming JK, Rodriguez JL. Is laparoscopic umbilical hernia repair with mesh a reasonable alternative to conventional repair? Am J Surg 2002;184(6):505-508

4 Anthony T, Bergen PC, Kim LT, et al. Factors affecting recurrence following incisional herniorrhaphy. World J Surg 2000;24(1):95-100

5 de Vries Reilingh TS, van Geldere D, Langenhorst B, et al. Repair of large midline incisional hernias with polypropylene mesh: comparison of three operative techniques. Hernia 2004;8(1):56-59

6 Jack A, Hernias Chapter 14th. In: Zinner MJ, Schwartz S, Ellis $\mathrm{H}$, eds. Maingot's Abdominal Operations. Vol. 1 10th ed. Connecticut: Prentice Hall International Inc; 1997;479 pp

7 Usher FC, Ochsner J, Tuttle LLD Jr. Use of Marlex mesh in the repair of incisional hernias. Am Surg 1958;24(12):969-974

8 Burger JW, Luijendijk RW, Hop WC, Halm JA, Verdaasdonk EG, Jeekel J. Long-term follow-up of a randomized controlled trial of suture versus mesh repair of incisional hernia. Ann Surg 2004;240(4):578-583 